\title{
THE FENESTRATION OPERATION FOR OTOSCLEROSIS
}

\author{
By E. R. Garnett Passe, F.R.C.S., F.A.C.S. \\ London
}

Since the discovery that the cause of deafness in the majority of cases of otosclerosis was due to ankylosis of the footplate of the stapes, various otologists in Europe and America have devoted much of their lives endeavouring either to prevent the ankylosis or to restore by surgery the natural path of sound waves. So far all attempts at preventing ankylosis of the footplate have been in vain; however, great strides have been made with the second half of the problem, which presented two main factors, namely, the establishment of a fistula into the perilymphatic space, which, despite the natural tendency on the part of nature to close, would remain open indefinitely and, secondly, the selection of such cases which, when this was accomplished, would respond by a return of hearing to a practical worthwhile level.

The evolution of this operation, now known as the Fenestration Operation, is of some considerable interest. Seventy-one years ago a German surgeon named Kessel discovered that removal of the stapes from its niche, in a patient suffering from deafness, restored the hearing for a short time. In 1897 this was confirmed by Passow. Again the improvement was of short duration. From that time onwards a number of otologists, e.g., Politzer, Bàràny, Rosey and Denker, found, upon creating a fistula in the capsule of the labyrinth, that hearing was restored to patients deafened by otosclerosis. Straaten stated that the same results would be obtained in cases where adhesions tended to fix the stapes in its oval window. Many and various were the operations devised, either for mobilizing the stapes or for producing a fistula into the labyrinth.

Jenkins in 1913 appears to have been the first in this country to treat cases of otosclerosis by opening the perilymphatic space via the semicircular canal. The hearing was markedly improved for several days. In 1923 Holmgren of Stockholm operated on four cases of otosclerosis with the use of a binocular dissecting microscope. He created a fistula close to the footplate of the stapes and then covered it with a Thiersch graft. The hearing remained improved for several.months, but later diminished. In 1929 Sourdille of Nantes described an operation performed in several stages to achieve a permanent fistula covered with a cutaneous flap continuous with the tympanic membrane.

From 1936 to I939 I carried out a series of thirty-six fenestration operations based upon the Holmgren technique, the results of which have been published.

The field of investigation, having been broadened by otologists in Europe, then moved to the United States of America, where the chief exponents were I.empert, Shambaugh and Campbell. Perhaps the most zealous of these workers and the one to bring the treatment to its modern degree of success was Julius Lempert of New York, who also devised the endaural approach. Since this work was started in the United States of America some thousands of cases have been operated on and reports have been published in various journals concerning its successes and failures, but a consensus of published reports to date indicates that the fenestration operation has at last taken its place as an accepted otologic procedure in certain cases of deafness due to otosclerosis.

From the practical standpoint the questions which face the otologist who regularly practises the fenestration operation are :

( $\mathrm{r}$ ) The classification or grouping of otosclerotics.

(2) The devising and carrying out of an efficient technique for the operation.

(3) The institution of a meticulous and rigid aseptic after treatment.

(4) The notation of follow up records based on standard tests.

(5) Tinnitus in relation to otosclerosis and the fenestration operation. 
(6) Results of the fenestration operation and comparison with those obtained by a hearing aid.

(7) The results of the fenestration operation.

\section{The Classification or Grouping of Otosclerotics}

The ultimate aim is the selection of those cases for whom, provided the operative technique is flawlessly carried out, we can say, beforehand that the result will be restoration of hearing to a permanent and useful level. This happy state has not yet been reached, but as the years go by we are approaching our goal more and more closely.

From the mass of literature which has already been published on the subject; mainly in the United States of America, and from examination of my own records, which include careful examination of over 2,000 cases of clinical otosclerosis, on more than 300 of whom I have operated, certain facts permit an accurate classification of cases of clinical otosclerosis into one of three groups, each of which may have a certain expectancy of result.

Group I. Those in whom clinical and audiometric examination for both pure tone and speech establish beyond doubt that the reserve of cochlear nerve function is adequate. In this group I expect 80 to 90 per cent. of cases to be restored to the practical conversational level.

Group II. This comprises those who may be classified as borderline cases. The clinical and audiometric examination in these cases show that the apparent extent of cochlear nerve damage is such that it will be necessary for the maximum improvement to be obtained if the practical hearing level is to be reached. In this group success can be anticipated in only about 20 to 40 per cent. of cases.

Group III. Comprises those cases where the cochlear nerve has so far deteriorated that the chances of improvement in hearing by the fenestration operation is practically nil. If the cochlear nerve endings are not capable of receiving and transmitting a normal stimulus it is useless to create a new window. Occasionally, however, even in cases in Group III, I have been surprised by an apparently hopeless case in whom the hearing was restored in the low frequencies of $25^{6}$ and 512 decibels to such an extent as to enable spoken conversation to be heard clearly, whereas they have previously been stone deaf to the loudest shout. Not only is it necessary for the fistula to remain open to obtain good hearing, but the cochlear nerve must be capable of receiving and transmitting sound impulses through the open fistula.

During this last year, using a type of fenestra that I described at a meeting of the Otological Section of the Royal Society of Medicine in December, 1946, I have not had, in approximately 170 cases, one fistula which has closed as judged by the fistula sign. However, one must bear in mind the fact that, although at last it may be possible to obtain a fenestra which will remain open, there is the difficulty of classifying and choosing suitable patients for the operation. For this purpose I employ routine taking of history, clinical examination of the external, middle ears and the upper respiratory tract to exclude infective and other diseased foci, together with careful examination of the receptive and conductive power of the auditory apparatus by means of the audiometer, tuning forks and speech perception. I have frequently observed that some patients whose hearing post-operatively has reached only to $35-30$ decibels have practical hearing, while others whose auditory level is as high as $\mathbf{2 5}$ decibels have difficulty.

Several factors have become apparent which are helpful in this estimation of hearing accuracy. Rinnés tests are carried out with tuning forks of 512 and 1,024 using masking. If they are both negative an improvement in hearing may be expected. If 2,048 is not heard at all by bone conduction the operation is contraindicated.

Further, I have noticed that in determining whether a case is one of nerve deafness or otosclerosis, if the patient states that the sound 'bursts' on them, as it were, e.g., if at 60 decibels the patient does not hear the note, but at $65-70$ decibels the patient states that the note is quite loud, then these cases are suffering from a clinical nerve deafness and should not be operated upon.

It has been said that the fenestration operation is of no value to people who have a hearing loss below 60 decibels, for below this it has been stated that the hearing is not likely 
to recover to the practical level, i.e., the 30 decibel or above. In my series many cases disprove this observation and I have, in fact, several cases where the hearing gains have been 55 decibels in practical frequencies. It has also been stated that, unless the hearing loss can be brought up to the 30 decibel level for the frequencies of 1,024 and 2,048, the patient cannot hear ordinary conversation. I have observed, however, many patients in whom improvement to the 30 decibel level or above has been in the frequencies of 256 and 512 only and in whom 1,024 and 2,048 have been below this level who hear ordinary conversation without undue straining. Patients who hear conversation more readily after this operation are those in whom the improvement has been over the range 1,024 to 2,048 .

Whilst I have frequently stated that I do not consider a 60 decibel loss in any frequency to mean that the hearing from this level cannot be raised to at least a 30 decibel level, I have failed to raise an 80 decibel loss in any frequency to the practical level. However, if this 80 decibel loss occurs only at 2,048 , whilst $\mathrm{I}, 024$ and lower is above this level, then, other things being equal, it may still be possible to give the patient practical hearing for the low or middle registers as I have indicated. Furthermore, in deciding whether the patient should have the operation or not, one must consider the fact that the operation in practically 90 per cent. of cases appears to prevent further hearing loss, even if the improvement does not reach the practical level.

In choosing a patient as suitable for this operation one must bear in mind, of course, other factors such as the psychology of the patient and, one may add, the degree of mental intelligence possessed by the patient. One young patient upon whom I operated with a successful result developed an acute anxiety state following the operation. Furthermore, some types of hospital patient with a low standard of intelligence seem to be unable to make the most of their restored hearing, or complain, because they cannot hear a watch at three feet like some of their friends, that the operation, though restoring conversational hearing, is a failure to them.

Paracusis Willisii or the power of hearing more clearly in noisy surroundings, such as a train or motor car, is another point that one should observe most carefully before selecting a patient as suitable for the operation. Absence of this sign usually indicates that a clinical nerve deafness, either primary or secondary, is present. If the patients volunteer that they hear better in a quiet room, then, as a rule, they are unsuitable for the fenestration operation. Those patients who had paracusis Willisii in the past but no longer have it also fall into this class.

In my experience I have occasionally found improved bone conduction in the operated ear in successful cases, but, as one might expect, I have also frequently found the reverse. This latter observation has been confirmed experimentally by Lowry. I have, however, found improved air conduction in the opposite ear some short time after a successful fenestration operation. Possibly bone conduction in itself does not give a direct indication of the acoustic nerve function, for other observers have found that bone conduction has improved after a successful fenestration operation. I have operated many times and produced successful results on patients where bone conduction for I,024 and 2,048 has been below the 30 decibel level, bringing the air conduction hearing loss to the 30 decibel level or above for these frequencies. In the early days of the fenestration operation Lempert and others stated that they did not think it worth while operating where the loss of bone conduction in the speech zone amounted to more than 30 decibels, but this is no longer true. It may be, of course, that the bone conduction does not give such a good indication of the condition of the acoustic nerve as was at first thought. Owing to improved technique, I feel we must lower the bone conduction limit from 30 decibels to 35 or 40 in frequencies of 1,024 and 2,048 , but retain it at 30 decibels for $5^{12}$.

Concerning age and the operation in general, young people have the greatest restoration of hearing, possibly owing to a better state of the cochlear nerve endings. I have two young patients who show upon repeated examination that the hearing level has been restored to zero in one frequency. On the other hand, I have elderly patients in the sixties, and even in the seventies, who have regained the practical conversational level with improvements of as much 
as 40 to 50 decibels in various frequencies. Furthermore, in none of my elderly patients has the fenestra appeared to close. This may be, of course, owing to the fact that bony regrowth in the elderly is naturally retarded.

In the fenestration operation the vascular circulation of the internal ear is considerably altered by the extensive removal of the periosteal layer of bone from the capsule in the region of the vestibule, lateral, superior and posterior canals. This may in part be responsible for the fact that the operation appears to retard the otosclerotic process so far as one can judge by cochlear function. This has been repeatedly confirmed by Lempert, Sourdille and Frazer.

$\mathrm{X}$-ray investigation does not give much assistance other than to show whether the mastoid is pneumatized or sclerosed. If it is sclerosed, then possibly the diagnosis is one of a chronic adhesive process and not of otosclerosis. However, sclerosis does not contraindicate the operation. The proof of stapedial fixation can only be truly ascertained during the operation, by palpation of the stapes itself. Excellent results have also been obtained in cases where the stapes proved to be entirely surrounded by dense bands of fibrous tissue.

Routine examination of the eustachian tubes is carried out in all cases and it is surprising how seldom complete obstruction is found. I am not speaking, of course, of children with läge masses of adenoids. I have not seen one case of bilateral adult deafness where the eustachian tubes were both blocked by adenoids, though $I$ have seen several in whom adenoidectomy has resulted in partial cohesion of what remains of the cushions of the eustachian tubes, but rarely is this deafness bilateral or of the increasing type. One patient presenting deafness of an unilateral nature appeared on examination to have a growth in the eustachian orifice, which on section proved to be an epithelioma.

Patients, especially the young, who state that their hearing reached its present level of deterioration in a matter of weeks or a few months, since when, and it may be years, the hearing has not deteriorated further, usually but not always prove to have severe nerve deafness. There appear to be a larger number of young people suffering from clinical nerve deafness, the etiology of which is apparently as obscure as that of otosclerosis, than one formerly suspected, and they present a wide field for future research.

We now realize that otosclerosis may cause deafness by other mechanisms than the one which causes stapedial ankylosis and until we can be certain that the latter change is the only one present we are bound to meet a percentage of failures. Similarly, there is no reason why a case which has remained successfully cured for a number of years may not suddenly begin to lose the hearing owing to a focus of otosclerosis developing in another vital region. Fortunately, otosclerotic foci causing deafness by attacking the otitic capsule elsewhere than adjoining the oval window are rare, but the prognosis must necessarily be guarded to this extent and, in all fairness, the patient warned of such a possibility.

To sum up the important question of selection :

(I) Bone conduction, whilst not a decisive criterion for the state of the acoustic nerve, is certainly a great help; the former guiding level of 30 decibels for frequencies 1,024 and 2,048 may now be lowered to 40 decibels.

(2) Paracusis Willisii, if present, is a most important guide to the possibility of operation. If absent it definitely excludes the patient from this operation.

(3) The duration of the increasing deafness it not very significant.

(4) Whilst the greatest acuity may be expected after operation in young persons, successful results may also be obtained in the elderly.

\section{The Evolution and Execution of an} Efficient Technique in the Fenestration Operation

The rationale of operation is now based on a technique which has proved experimentally to give the best results. (Lindsay, Shambaugh and Juers.)

As might be expected with an operation of this nature in which technique is all important, progress has been made by various methods, the good ones being retained and improved and the poor discarded. Endeavour has so far been directed into two main channels : 


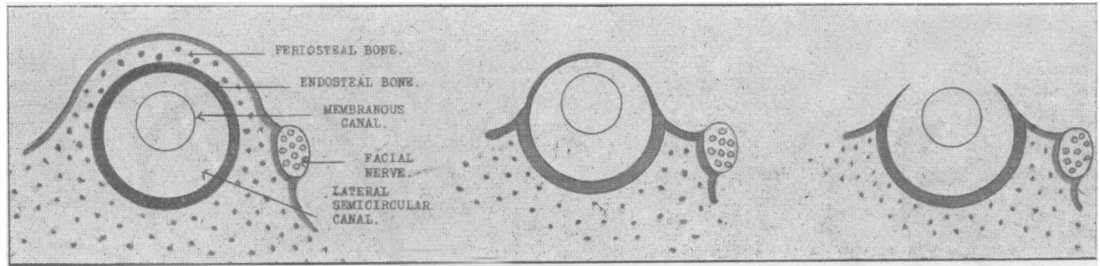

Fig. I.

FIG. 2.

FIG. 3.

FIg. 1.-Cross section of lateral semicircular canal. FIG. 2.-Periosteal bone removed down to endosteal bone over a large area. FIG. 3.- Endosteal bone thinned down until the roof is finally removed

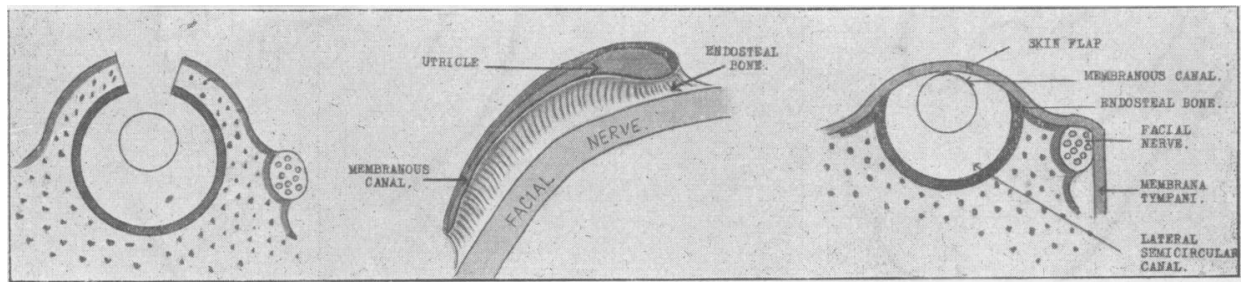

FIG. 4 .

Fig. 5 .

FIG. 6.

FIG. 4-The old type of fenestra made for use with the cartilage stopple. Fig. 5.-Lateral view of the fenestra in roof of vestibule and canal showing fenestra seated on top of a ridge. FIG. 6.-Skin flap in situ. Note that it is in contact with the membranous canal.

(I) To establish a fistula in the periotic capsule which will remain permanently open and so allow mobilization of the perilymph.

(2) To provide some form of covering for this opening which will transmit air waves with a maximum of efficiency.

The foundations of the present-day technique have been well laid by Julius Lempert of New York, who performed much experimental work in devising a method of keeping open the fenestra. Many ingenious methods of preventing bony regeneration were used from eburnation of the edges of the bone to the introduction of foreign substances of various kinds. Many successes have been obtained with the introduction of an autogenous cartilage graft or stopple. My second series of 100 cases were performed this way, but I use it no longer, as it did not fulfil its early promise. Shambaugh in 1946 gave an account of 822 fenestration operations performed under continuous irrigation and reported that in 88 per cent. of cases of more than two years' duration a hearing improvement of 10 decibels or over has been fully maintained. It was he who evolved the technique of enchrondralization of the fenestra ; by this means the periotic layers of bone are removed until only the osteogenetically inert enchrondral layer of the bony labyrinthine capsule remains in the area in which he makes his fenestra.

As mentioned previously in December, 1946 , I described a modification of this fenestra in which I performed a more extensive removal of the periosteal layer of bone around the canal and domed vestibule, leaving only a thin eggshell layer of the endosteal bone extending from the dome of the vestibule anteriorly to the downward bend of the lateral semicircular canal posteriorly. On top of this ridge of bone the fenestra is then made. The main difference between my ienestra and that of Shambaugh is that my fenestra is much longer and more of the endosteal bone is exposed. By using this method I have been able to obtain a fenestra in some cases almost a centimetre in length. Great care must be taken not to injure the membranous canal in such a long fenestra as it tends to float out of the canal. By using the binocular microscope and irrigation, all bone fragments and dust particles are carefully removed as soon as they are made from the region of the fenestra and on the 


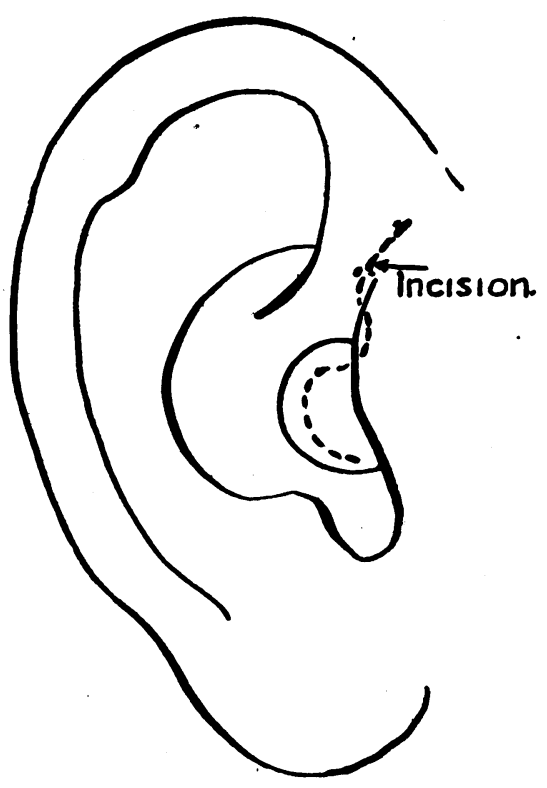

Fig. 7.- Single ' $\mathrm{S}$ '-shaped incision cutting 'tongue' of skin.

periosteal surface of the meatal flap. Complete haemostasis is most essential and is obtained by diathermy, fibrin foam or oxycel. It has been my practice in recent months to 'float' the flap into place in a bed of Ringer's Solution. The flap is fixed in position by wax plugs placed in a groove prepared especially above the fenestra and great care is taken to prevent pressure on the flap over the actual fenestra by the subsequent dressing. The flap is firmly adherent to the bone in 48 to 56 hours. This was proved by a case in which at the commencement of preparing the fenestra my electric drill broke down and I had to leave the flap over the prepared area of the vestibule and semicircular canal whilst the engine was being repaired. Forty-eight hours later, on raising the flap to complete the fenestra, I found that it was firmly adherent by vascular granulation tissue to the bony bed. Plastic surgeons have confirmed this observation since.

At present I am working with solutions of anti-histamine agents to endeavour to prevent some of the traumatic post-operative labyrinthitis supposedly due to histamine liberation from the under surface of the flap. It is too early yet to state any results, but so far they have been most encouraging. Other methods

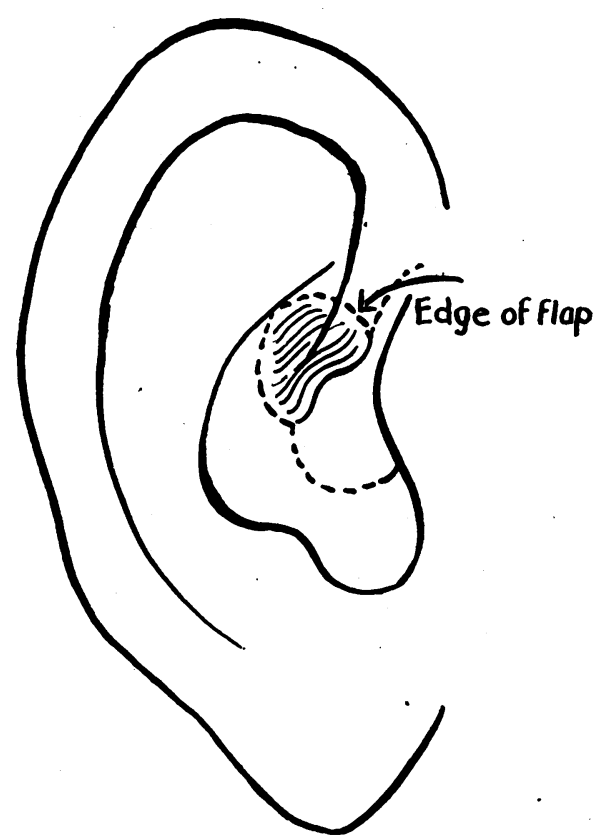

FIG. 8.-Showing tongue of skin tucked upwards and backwards into mastoid cavity.

of preventing post-operative labyrinthitis are by absorbent sponges or self-absorbent cellulose. Immobilization in a head frame for 48 hours post-operatively as recommended by Shambaugh has, I believe, a definite use.

Since I gave up using the cartilage stopple and employed the above means in an endeavour to lessen post-operative labyrinthitis I have noticed that a greater number of patients have stated that their hearing improved the day after operation, and also that the post-operative period of lessened hearing is reduced in many cases by several days. Nor does the nausea and vomiting appear to be so great nor so prolonged as it did in my earlier cases. Patients are now quite willing to get out of bed on the fourth day, whilst formerly it was often a week before they could be persuaded to do so. The amount of giddiness and nausea following the operation appears to have an individual characteristic in that patients who are readily seasick appear to be affected more severely than those who do not suffer from this malady.

The flap I use is formed of the anterior meatal wall. It is always possible to cover the dome of the vestibule and the ampulla of the lateral canal with this very thin skin, but it does not always prove possible to cover the 
prolongation of the fenestra around the bend of the lateral canal with the anterior meatal wall. Results may be much better using this thin skin in covering the fenestra, though it is also apparent that the epidermal lining of the cavity in this region invariably becomes paper thin within 9 to 12 months unless infection supervenes. This, then, appears to be the technique of choice at the present day.

It has not been necessary to carry out revision in any of my cases performed during the last 12 months, though it was necessary in approximately 10 to 15 per cent. of cases performed during the previous 12 months when I employed the cartilage stopple insertion. In each case of revision performed in these cases the cartilage stopple was found to be immobilized or even extruded by fibrous tissues and not by bony growth, though bone was found on section embedded in the fibrous tissue.

Should damage occur to the endolymphatic system during the operation, escape of endolymph occurs and leads to a reduction in the amount of hearing gained, though it by no means prevents partial restoration of hearing. I feel, however, in these cases that in due course fibrous tissue is more likely to fill the canal and cause further deterioration of hearing than if the membranous endolymphatic system remains intact and unites with the under-surface of the flap. On the other hand, cases of Ménière's disease treated by extraction of the lateral and superior membranous canals, after sealing off the utricular ends by diathermy, did not result in a further reduction of the patient's already somewhat lessened hearing.

Concerning the risks of the operation, I have had no deaths or serious complications in my 300 cases. There has been no case of persistent dizziness-sufficient to be incommoding-lasting more than four months. There has been one case of internal saphenous phlebitis. This was probably due to the anaesthetic, for I perform the operation under intermittent intravenous pentothal injected into one of the veins of the legs or feet.

3. The Institution of a Meticulous and Rigidly Aseptic After-treatment

The success of the operation does not depend only on the technique employed in the actual operation. It also depends to a very large extent upon obtaining a dry cavity soundly healed in a minimum of time. As I employ the endaural approach entirely, one of the problems which early manifested itself was the prevention of stenosis of the external meatus which occurred in a small percentage of cases. In order to avoid this, I devised a modification of the Lempert endaural incision, which provides me with a flap of skin hinged postero-superiorly, which at the end of the operation is folded back into the meatus and held up against the lower border of the temporalis muscle by means of a suture passed through the flap and through the skin of the post-auricular groove. This also provides a starting point for epithelialization in this region and by this means the external meatus is covered by skin for five-sixths of its circumference and no skin is wasted as in the Lempert endaural incision. (See diagram.)

The first dressing is performed on the sixth day under pentothal anaesthesia, the second on the fourteenth day and the subsequent ones once a week until the cavity is dry, without, of course, any further anaesthesia.

I am now using an absorbable cellulose packing which as it liquefies can be sucked out of the cavity on the tenth day and so avoids an anaesthetic. From first to last the operation need give no pain whatever. After the cavity is cleaned one of the sulpha drugs is insufflated in powder form. All dressings are performed in the early stages by myself, and I cannot advocate too strongly the necessity for this. All dressings used are sterilized by autoclave. It was found in female patients that the hair was a great source of infection; in order to avoid this in the early days I insisted on the patient wearing a bandage for four weeks and I am convinced that this has done more to reduce post-operative infection than any other single factor. The rate of healing appears to be an individual matter and no hard and fast rule can be laid down; it may take any time from four weeks to six months. Recent experiments with the above cellulose soaked in a 2 per cent. Benadryl solution have given great promise of a rapid epithelization of the cavity, but it is too soon to pass judgment on this. 


\section{The Notation of Follow-up Records Based upon Standard Tests}

If progress is to be made in this.operation, then complete records should be kept, not only of the results, but of the minute technical details as to shape and size and position of the fenestra, condition of membranous canal, type of dressings, shape and position of flap, type of dressing employed, etc., so that by comparison of these details a technique offering the best results may be evolved.

Careful records of audiometric tests taken at intervals of one month, three months, six months, one year and then yearly for 10 or more years for both air and bone conduction of both ears is also necessary to' appraise the value of the operation. To this I add a questionnaire to be answered yearly as to whether the patient regards the results as satisfactory. In my series of over 300 cases I have only one patient (who subsequent to the operation developed frequent attacks of acute otitis media) who has stated that the operation was not worth while.

If otologists practising this operation would co-operate and compare their results based upon some practical classification of patients as suggested above, together with the minute details of technique employed, I feel that progress would be made more rapidly than by independent workers. I am using a standard perforated record card which rapidly shows the results of any particular item in the history, selection, operation and after-treatment of each ${ }^{*}$ case.

\section{Tinnitus in Relation to Otosclerosis and the Fenestration Operation}

Approximately 90 per cent. of all cases of deafness whom I have examined in the last two years complain of tinnitus in one or both ears, or 'in the head.' 60 per cent. of these claim that the tinnitus is of a pulsating character synchronous with the heart beat and made worse by exertion. The tinnitus among these people is nearly always of the ' hissing' or 'steam' or 'booming' variety. In the other type the noise is continuous, not affected by the heart beat or exertion, and is usually of a high-pitched or continuous bell or clanging variety. Many patients complain of an ex- plosive sound in the ear, usually as they are about to drop off to sleep. Pre-operative audiometry of patients with tinnitus presents a slight added difficulty which can be overcome with patience. One of the questions asked by most patients is what effect the operation will have on their noises. Here the answer is unpredictable, but examination of my records show that in approximately 25 per cent. the noises are either relieved or greatly reduced. In a further 60 to 70 per cent. the noises remain unaltered in intensity, but may be altered in tone. In a small percentage they may even become worse for a short time and make the hearing tests post-operatively extremely difficult. I believe that tinnitus which is synchronous with the heart beat is due to reflex vascular spasm.

I endeavoured in a series of cases to alleviate this by destroying Jacobson's nerve and vessels as they pass over the promontory by means of coagulation diathermy during the operation, a procedure later described as a separate operation by Lempert. The results of this have been most disappointing, and this is understandable if tinnitus is due to spasm of branches of the internal auditory artery as well as branches of the tympanic. Bearing this in mind, I have found that severance of the preganglionic fibres of T.I and 2 produces instantaneous and complete cessation of the pulsating type of tinnitus, thereby 'clearing the head' and greatly improving the aural acuity. Further work is being done on this question and also its relation to the aetiology of treatment of early otosclerosis, and when sufficient material is available it will be presented. One patient suffering from early otosclerosis upon whom a stellectomy was performed, showed a marked gain in hearing with complete cessation of the tinnitus after operation, although the hearing still continues to deteriorate and the tinnitus to persist on the unoperated side.

It is still questionable whether it is desirable to perform a sympathectomy on both sides or not. The innervation of the internal auditory artery may or may not be by fibres from both thoracic chains. It is yet to be proved that it is necessary to operate on both sides to produce the effect on one ear only. Up to now most of the work on the sympathetic supply of the vessels to the ear has been done on the superior 
or inferiot cervical ganglion, but this neglects the branches to the vertebral artery which are most important. Possibly the operation of choice would be periarterial sympathectomy of the internal auditory artery. This produces the same excellent result, but is a more formidable operation. I am convinced that resection of the plexus promontorium is only of use in cases of tinnitus which may be due to irritation of this plexus by inflammation. Many patients complain during the first five or six days of severe noises in the operated ear, which subside within the next few weeks. This may be an example of tinnitus due to irritation of the plexus promontorium.

\section{The Results of the Fenestration Operation and Comparison with those obtained by Hearing Aid}

The testimony obtained by Shambaugh in his questionnaire to 853 patients who had undergone the fenestration operation reveals that ' many patients who have had the fenestration operation and who regard the results as satisfactory assert without qualification that they hear better now than they did with their aid, and without the distortion, the nuisance and the upkeep expense of an aid.'

Time and time again the same feelings have been expressed to me by patients, not one of whom has -stated that they prefer the hearing obtained with an aid. Without exception they appear only too relieved to be able to do without it.
The Results of the Fenestration

\section{Operation}

Possibly in this operation more than in any other one must state that the results depend upon the individual care in selection and the skill of the operator. In discussing the results of the fenestration operation it is necessary to divide the results into groups, namely: (I) those in whom the hearing has been restored to the practical conversational level ; (2) those in whom the hearing loss was very great and in whom, although the hearing has not been restored completely to the conversational level, yet it has been materially improved to the extent that the patient is now able to use a hearing aid of a smaller, less powerful and more convenient type ; and (3) those cases of both the above groups in whom the hearing loss has been prevented from further deterioration for an indefinite period. Whether or not the operation in successful cases arrests or prevents the usual nerve degeneration of otosclerosis cannot yet be answered with certainty owing to the limited duration of results so far available. In the U.S.A., surgeons who have results of longer duration than myself state that a further nerve degeneration in the operated ear of successful cases has rarely been observed. From my own present series of two years' duration I can report a similar result. If the hearing is not improved although the fenestra remains open, are we justified in assuming that further degeneration of the cochlear nerve will not take place? This also

\section{INTERIM RESULTS}

\begin{tabular}{|c|c|c|c|c|c|}
\hline Series. & $\begin{array}{l}\text { Total No. of } \\
\text { cases. }\end{array}$ & $\begin{array}{l}\text { Hearing never } \\
\text { improved. }\end{array}$ & $\begin{array}{c}\text { Hearing improved } \\
\text { but improvement } \\
\text { lost later. }\end{array}$ & $\begin{array}{l}\text { Hearing } \\
\text { worse. }\end{array}$ & $\begin{array}{l}\text { Hearing improved } \\
\text { and fully } \\
\text { maintained. }\end{array}$ \\
\hline $1936 / 39$ & 36 & 5 & 28 & $\mathbf{I}$ & $\begin{array}{l}\text { Two of eight } \\
\text { years' duration. }\end{array}$ \\
\hline $\begin{array}{l}\text { 1945/46 with coch- } \\
\text { lear stopple }\end{array}$ & 100 & 7 & 36 & 3 & $\begin{array}{l}53 \text { of one to two } \\
\text { years' duration. }\end{array}$ \\
\hline $\begin{array}{l}\text { I946/47 enchrondral- } \\
\text { ized fistula. }\end{array}$ & 166 & II & 2 & None & $\begin{array}{l}\text { I } 53 \text { during last } \\
\text { twelve months. }\end{array}$ \\
\hline
\end{tabular}

Fig. 9. 
remains unanswered. Much has been said of late concerning improvement of hearing obtained in the unoperated ear in those cases in whom the fenestration operation has resulted in improved hearing in the operated ear. Careful examination of the unoperated ear in a large percentage of cases has shown that some slight improvement does occur up to Io or I 5 decibels, but that this improvement is purely temporary in nature and in not any of my cases has it persisted over more than six months. This phenomenon may account for the facility with which some patients hear the nurse or the surgeon during the first 24 to 48 hours after the operation, for the operated ear is packed with a dressing and bandaged, thus making hearing for ordinary speech impossible, as I have proved experimentally on myself. Conversely, in one case in which I performed the fenestration operation on the second ear, it was noted by the patient that the hearing in the operated ear markedly deteriorated during the period of post-operative labyrinthitis, but recovered again as this subsided.

Concerning the permanency of the hearing improvement the final answer is yet to be obtained. In the early days of this operation, bony closure almost invariably occurred with recurrence of deafness to at least the preoperative level. As a result of the introduction of the enchrondralized type of fenestra it has been affirmed that cases operated on and followed up for more than six years show a cessation of osteogenesis tending to close the fenestra once healing is completed. In order to be on the safe side an arbitrary time of two years has been chosen as a reasonable time for osteogenesis to come to an end, and the hearing improvement maintained for two years may be regarded as almost certainly permanent. In my opinion the critical period is six months, though, as I have stated before in my series for last year, in no case has the fistula closed. In only two cases in which an improvement in hearing* has occurred has there been up to date any marked deterioration in hearing. I have found that a slight depreciation of 5 to ro

* 91 per cent. of Group I showed an improvement in their hearing. decibels may occur from time to time, depending upon the patient's state of health and whether they are tired, overworked or are under undue nervous strain, etc. There still remains a small percentage of cases who, though apparently suitable in every way for the operation, give an unpredictable result. The reason for this has not yet been determined so that failures do still occur, although pre-operative indications are satisfactory and the operative and post-operative techniques as perfect as possible. It must be remembered that the hearing is never restored to normal. In my whole series I have only two patients in whom the hearing has been restored to the normal line and then only for one frequency in each case. As the amount of work being performed in this country is increasing, I feel it would be of considerable help if a standard complete and adequate record of all cases were kept over a period of at least ten years, so that not only may the results be tabulated, but the technique and incidents of the operation noted and faithfully recorded. It is only by these means that a final evaluation of this operation can be formed.

\section{BIBLIOGRAPHY}

HOLMGREN, G. (1939), Acta Otolaryngologica, 27, 338. HOLMGREN, G. (1941), Acta Otolaryngologica, 29, 99.

HOLMGREN, G. (1946), Practica oto-rhino-Laryngologica, 8, 441 . JENKINS, G. T. (1913), Tr. Internal Congr. med. sect., 16, 609.

KESSEL, J. (1874), Archiv für Ohrenheilkunde, 8, 231.

LEMPERT, J. (1938), Archives of Otolaryngology, 28, 42.

LEMPERT, J. (1940), Archives of Otolaryngology, 31, 7I I.

LEMPERT, J. (1942), Archives of Otolaryngology, 36, 473.

LEMPERT, J. (1945), Archives of Otolaryngology, 41, 1 .

LEMPERT, J. (1946), Archives of Otolaryngology, 43, 199.

LEMPERT, J., and WOLFF, D. (1945), Archives of Otolaryngology, 42, 339.

PÁSSE, E. R. G. (1989), fournal of Laryngology, 54, 567.

PASSE, E. R. G. (1946), Proceedings of Roy. Soc. Med., Vol. XL, No. $4,319-320$.

PASSE, E. R. G. (1947), Lancet, Feb. 1 .

SHAMBAUGH, G. C. (1940), Archives of Otolaryngology, 32, 927.

SHAMBAUGH, G. C. (1946), Kansas City Med. Fournal, MarchApril.

SHAMBAUGH, G. C. (1946), Archives of Otolaryngology, 43, 549.

SHAMBAUGH, G. C. (1942), .7.A.M.A., 119, 243.

SHAMBAUGH, G. C. (1942), Annals of Otology, 51, 817.

SHAMBAUGH, G. C. (1945), Quarterly Bulletin, Univers, med. school, Chicago, N. 4, 19, 259.

SHAMBAUGH, G. C. (1945), Archives of Otolaryngology, 41, 189.

SHAMBAUGH, G. C. (1944), The American Acad. of Ophthalm. and Otology. Graduate Lecture 65.

SHAMBAUGH, G C. (1946), F.A.M.A., 130, 999.

SHAMBAUGH, G. C. (1947), Surg. Gynec. and Obstet., "The Fenestration operation; an evaluation of its present status," 84,825 .

SOURDILLE, M. (1935), Société Fran§̧aise de Laryngologie, Oct. SOURDILLE, M. (1930), fournal of Laryngology, 45, 601. 